\title{
3 Research Soure \\ Identifying Key Features of Telepresence Robot Systems in Intensive Care Units: a Scoping Review Protocol
}

Héctor Avilés

Universidad Politecnica de Victoria

Sergio Hernández-Méndez

Universidad De Xalapa

Héctor Simón Vargas-Martinez

Universidad Popular Autonoma del Estado de Puebla

Marco Antonio Negrete-Villanueva ( $\Delta$ marco.negrete@ingenieria.unam.edu )

Universidad Nacional Autónoma de México https://orcid.org/0000-0002-5468-2807

Gilberto Felipe Vázquez de Anda

Universidad Autonoma del Estado de Mexico

Protocol

Keywords: Health robotics, telepresence, ICU, mobile robot, robot interface

Posted Date: October 21st, 2021

DOl: https://doi.org/10.21203/rs.3.rs-963629/v1

License: (9) This work is licensed under a Creative Commons Attribution 4.0 International License.

Read Full License 


\section{Abstract}

Background: The progress of robotics in the last decades and the current Covid-19 outbreak have contributed to an increasing interest in integrating telepresence robot systems into healthcare. However, it is still needed to better understand how robotic features contribute to medical practice and to the wellness of patients. Hence, we propose a scoping review to spot features of telepresence robot systems that impact the fulfillment of goals in health care for patients in intensive care units.

Methods and analysis: Our review will be guided by Arksey and O'Malley's framework and the revisions by Levac et al., and Peters et al. We will search in 18 scientific databases specialized on either medicine or digital technology, plus another 5 online sources of grey literature. We will consider documents dated between 2000 and 2021, in English and Spanish, and we will perform a quantitative analysis and a thematic synthesis of the papers included in this study.

Discussion: This work will help to recognize characteristics, components and capabilities of telepresence robots that are relevant in medical practice, to guide new research and development avenues and boost cooperation between health providers and roboticists. Results will be submitted to a peer-reviewed journal and included in promotional activities of our universities. This study does not require ethics review, however, we will be very attentive to feedback from patients, caregivers, health providers and decision makers involved in this scoping review.

OSF Registration: DOI: 10.17605/OSF.IO/S3FHR (Submitted on October 4, 2021)

\section{Background}

Medical robotic telepresence systems (MRTS) are promising tools for improving the quality of care to patients in intensive care units (ICU) due to their capacity to materialize health professionals delivering medical attention at a distance [1]. In its basic setting, a MRTS is composed of a wheeled robot base equipped with display screens and speakers, wireless network adapters, microphones, video cameras, and graphical or physical interfaces to monitor and control the robot via internet or local area networks. In some cases, the system provides access to electronic health records (EHR) [2].

The definition of the features of a MRTS should consider the physical appearance of the robot, the patients, the physicians, the people around the robot, the working environments of both the robot and the operator, the communication interfaces [3], the functionalities of the robot, its perceptual and cognitive capabilities and level of autonomy [4]. The type of medical care, the need to manage medical health histories and monitor vital signals, or even the ethical, moral and legal implications of the use of MRTS [5-7] also influence the characteristics and components of a robot. Around the world, there exist multiple research groups working independently on technologies relevant to this type of robots. As a result, robotics evolves rapidly and literature must be examined regularly. Therefore, we propose a scoping review to identify relevant features of MRTS to the achievement of health care in intensive care units. 


\section{Study Rationale}

Features of a MRTS influence the quality of care, the wellness of patients admitted to ICU and the attitudes of the health personnel to the robot. Moreover, the identification of relevant features and the way they affect processes, outputs and actors can be useful to define criteria to measure efficiency and effectiveness of robotic telepresence [8].

We performed a preliminary and informal search on Google Scholar in september 2021, with the next simple search string: "robot AND hospital AND Telepresence". We have neither collected nor analyzed any paper thoroughly, though. However, we observed that literature is vast and constantly increasing, and that there exist variations between medical and robotics terminology and interdisciplinary jargon. This may inhibit cooperation between robotics developers, health professionals and key decision makers to develop and deploy useful robots designed from empirical knowledge, that is the foundation of evidence-based medicine. Moreover, the well-known Covid-19 outbreak has attracted attention [9] to telepresence robots because they allow distributed collaboration, help to tackle medical shortage, and reduce physical contact thus increasing the safety of patients, relatives and health professionals. Patients that live in rural and remote communities with difficult access to medical specialists could be greatly benefited from this work too.

\section{Research Objective}

The objective of this work is to identify key features in MRTS that affect medical attention to patients admitted on ICUs, based on the evidence reported in the literature. This work implies several sub goals:

- Identify the types of physical interaction that can happen in an ICU when using a telepresence robot.

- Spot the physical and non-physical elements (for example, health care databases) involved in the medical attention with MRTS.

- Recognize the engineering or technical specifications of MRTS relevant to carry out ICU-processes.

- Determine the patient-related information used to lead medical care with MRTS.

- Describe the features of the communication and monitoring interfaces that compose MRTS.

- Review the aspects of MRTS that the medical staff needs to know in order to use them.

- Discuss the effect of the physical appearance of the robot over the attitudes of patients and the people around to the robot.

\section{Methodology}

\subsection{General strategy}

The basis of our review will be Arksey and O'Malley framework [10] that consists of the next six stages: 1) identifying research questions, 2) identifying relevant studies, 3) study selection, 4) charting the data, 5) 
collating, summarising and reporting the results, and 6) consultation with stakeholders. We incorporate posterior refinements suggested by Levac et al. [11] and Peters et al. [12, 13]. Specifically, we include: a) a rationale (Section 2), b) the population, context, and concept (PCC) elements (Table 1), c) an ensemble of a multidisciplinary review team that consists of roboticist engineers and a physician with extensive knowledge in telepresence robots, and d) a flowchart that describes the search decision process based on the PRISMA-ScR [14] statement.

Table 1

Definition of our target population, concept, and context.

\begin{tabular}{|ll|}
\hline Criteria & Description \\
\hline Population & $\begin{array}{l}\text { Patients (up to } 79 \text { years old) hospitalized in an ICU, and health professionals and care- } \\
\text { givers that use telepresence robot systems to attend patients. }\end{array}$ \\
Concept & Design decisions in MRTS that affects medical care to patients entered into ICU. \\
Context & $\begin{array}{l}\text { Studies written in English and Spanish within all geographical and sociocultural } \\
\text { conditions are considered. }\end{array}$ \\
\hline
\end{tabular}

\subsection{Identifying research questions}

After discussion by e-mail and videoconferencing, our team identified the following research questions:

- RQ1: Which are the design features that influence robotic telepresence-based processes in Intensive Care Units?

- RQ2: Which are the factors and actors involved in robotic telepresence-based processes in Intensive Care Units?

- RQ3: Which information about the patient and its environment is required for an adequate robotic telepresence-based intensive care?

- RQ4: Which are the possible interactions between the robot and the different actors of an robotic telepresence-based ICU?

All authors approve this manuscript for submission to

\subsection{Identifying relevant studies}

Our search will focus primarily on formally published papers. For documents in English, we will search in the next electronic databases: ACM, BMC-Springer Nature, BMJ, BMJ Open, Cochrane Library, Ebscohost, IEEE Xplore, MEDLINE, Science Direct, Scopus, SpringerLink, PubMed, Web of Science, Hindawi, and Wiley Online Library. In Spanish, we will search SciELO, Redalyc, and Dialnet. We will search for grey literature as suggested by [15]. Our search in English will consider OpenGrey and Grey Literature Report, and Google Scholar, Google Dataset Search, and Google Web Search for searches in both English and Spanish. 
The basic structure of our search string is described in Table 2. It is composed of three main concepts. For each concept we selected search words with the wildcard "*" to substitute zero or more characters whenever necessary. Only the asterisk wildcard is considered as it is common to many search engines. In English, we tested words with the wildcard using the online version of the Chambers Crosswords Dictionary and Thesaurus $[16,17]$. In Spanish, we used the Diccionario de la Lengua Española of the Real Academia Española [18]. In addition, we carefully chose synonyms for some of the words. The form of our search string will be a conjunction of disjunctions as follows: we will associate search words of a main concept with OR connectors, and then the three groups will be joined together with AND connectors. Whenever possible, our search string will be restricted to titles, abstracts, and keywords.

\subsection{Study selection}

\subsubsection{Inclusion criteria}

We will consider any type of papers devoted to MRTS with wheeled robots applied in ICU. Papers must have been published in academic peer-reviewed journals or conferences, from 2000 to 2021, in either English or Spanish languages, and in medical or engineering disciplines. As grey literature, we will incorporate book chapters, official government documentation and technical reports not published in traditional scientific journals, but endorsed by international health associations or academic groups or centres.

Table 2

Main concepts and search words with wildcards that compose our search string.

\begin{tabular}{|c|c|c|}
\hline Concept & Search words (English) & Search words (Spanish) \\
\hline Robot & $\begin{array}{l}\text { robot* }^{\star}, \text { robot}^{\star} \text { system, clinical robot* } \\
\text { robot }^{\star} \text { design, robot* avatar*, mobile }^{\star} \\
\text { robot }^{\star}, \text { robot* }^{\star} \text { platform }\end{array}$ & $\begin{array}{l}\text { robot* } \text { sistema* robótico*, robot* clínico* }^{\star} \text { diseño de robot*, avatar*, robot* móvil*, } \\
\text { plataforma* robótica* }\end{array}$ \\
\hline Telepresence & $\begin{array}{l}\text { telepresence, telemedicine, telehealth, } \\
\text { remote presence }\end{array}$ & $\begin{array}{l}\text { telepresencia*, telemedicina, telesalud, } \\
\text { presencia remota }\end{array}$ \\
\hline ICU & $\begin{array}{l}\text { intensive care unit, ICU, hospital*, } \\
\text { medical center*, health* facilit* }\end{array}$ & $\begin{array}{l}\text { unidad de cuidados intensivos, UCl, } \\
\text { hospital*, centro* médico*, } \\
\text { establecimiento* sanitario*, centro* de } \\
\text { salud }\end{array}$ \\
\hline
\end{tabular}

Information from private institutions will be taken into account if it is publicly available on the Web. Studies of all types of basic and clinical research will be included. We understand basic research as focused on experimental studies in controlled environments and clinical research as studies performed in real world conditions $[19,20]$. Our attention will focus on primary sources. Papers cited in the documents spotted in our original search will also be considered.

\subsubsection{Exclusion criteria}


We will omit position statements, editorials, letters, interviews, speeches, research protocols, dissertations, internet articles or videos, and papers in progress. Moreover, animal research and open access encyclopedias will not be considered.

\subsubsection{Selection process}

Paper selection will follow the steps depicted in the flow diagram of Figure 2. The authors will carry out an initial search in databases and gray literature sources. The bibliographic references of the papers identified along with their keywords and abstracts will be stored in Zotero software [21]. Two authors will remove duplicate records. Paper screening will be executed by two authors using titles and abstracts. Each paper will be assessed for eligibility by two authors independently by scanning the entire paper. One author will examine the assessment process once $10 \%$ of the papers have been inspected. Selection criteria will be revisited periodically and adjustments to our inclusion and exclusion criteria will be discussed and agreed by the team. Authors involved on each step will cross-check their results, and any discrepancy will be resolved on consensus. If there is no agreement, a decision will be taken by all team members and an external stakeholder, if it is needed.

\subsection{Charting the data}

Table 3 shows the arrangement of our preliminary set of attributes chosen to fulfill our research objective. Paper information is useful for ease of reference and for classifying studies by their goals and type of research. The rest of the attributes are organized into a two-level hierarchy of categories in which the main level corresponds to the Donabedian's structure-process-outcome model [22]. This description is similar to other models found in engineering where outcome measurements are required [23], and hence becomes familiar to various of the team members. The Structure category is divided into the 6 classes of elements of a telepresence robot system proposed in [3], that is: i) the physical robot, ii) the robot's user, iii) the interfaces, iv) the user's environment and v) the remote environment, and vi) the people interacting with the robot. In addition, the table comprises the relation cost-benefit of the robots, along with legal, ethics and moral implications, and the technical training required by the health professionals to maintain, assist, operate or evaluate the robot. Attributes grouped into the Process category describe the type of patient care that is delivered and the actions performed on purpose. The Output category consists of attributes related to changes in the health situation of the patient, the attitude and perception of physicians, patients and nurses, and the overall acceptance for the robotic system. Each set of attributes are related to a question described in Section 4.2 .

As a pilot procedure, two authors will select at random $10 \%$ of the articles included in the study, and will collect data using the extraction table described above. The goal is to identify any differences in criteria for judging data, and to evaluate our initial dataform. A third author will review the consistency of the extraction. Any differences will be discussed first by the three authors, or with all the team members in one of the meetings that will be scheduled regularly. Lessons learned will be shared with the team members, and each one of the four authors will extract data from approximately $20 \%$ of the remaining 
$80 \%$ of the papers. Observations to the set of attributes will be accepted for discussion during the whole extraction process and the modifications approved by the team will be implemented accordingly.

Table 3

Data extraction table.

\begin{tabular}{|llll|}
\hline Category & Sub-category & Attribute & $\begin{array}{l}\text { Related } \\
\text { questions }\end{array}$ \\
\hline $\begin{array}{l}\text { Paper } \\
\text { information }\end{array}$ & Bibliographic data & $\begin{array}{l}\text { Title, First Author, Year, Abstract, Type of } \\
\text { publication, Publisher, Country }\end{array}$ & $\begin{array}{l}\text { Only for } \\
\text { statistical } \\
\text { information and } \\
\text { reference }\end{array}$ \\
\hline Structure & General methodology & $\begin{array}{l}\text { Research objective and questions, Type } \\
\text { of study design }\end{array}$ & RQ4, RQ2 \\
& The physical robot & $\begin{array}{l}\text { Locomotion system, cover material, } \\
\text { physical appearance, size, shape, } \\
\text { ergonomy, actuators, sensors }\end{array}$ & RQ1 \\
\hline & $\begin{array}{l}\text { The physician } \\
\text { operator }\end{array}$ & $\begin{array}{l}\text { Specialty, years of experience with } \\
\text { robots }\end{array}$ & RQ2, RQ4 \\
\hline $\begin{array}{l}\text { The interfaces } \\
\text { Communication interfaces, } \\
\text { communication network, bluetooth, LAN }\end{array}$ & RQ1 \\
\hline $\begin{array}{l}\text { The operational } \\
\text { remote control } \\
\text { station }\end{array}$ & $\begin{array}{l}\text { Furniture and lighting conditions in the } \\
\text { operator and patient environments }\end{array}$ & RQ2, RQ4 \\
\hline
\end{tabular}

Table 3: Data extraction table (Cont.).

\begin{tabular}{|cllc|}
\hline Category & Sub-category & Attribute & $\begin{array}{c}\text { Related } \\
\text { questions }\end{array}$ \\
\hline Structure & $\begin{array}{l}\text { The } \\
\text { interactions } \\
\text { with the robot }\end{array}$ & $\begin{array}{l}\text { Number of nurses, family, caregivers, and patients, input } \\
\text { and output modalities, devices used }\end{array}$ & RQ2, RQ4 \\
\hline $\begin{array}{c}\text { Autonomy } \\
\begin{array}{l}\text { Technical } \\
\text { support }\end{array}\end{array}$ & $\begin{array}{l}\text { Perceptual and cognitive capabilities } \\
\text { Installation, preventive and corrective maintenance, }\end{array}$ & RQ1, RQ4 \\
$\begin{array}{l}\text { Cost-benefit } \\
\text { relationship }\end{array}$ & $\begin{array}{l}\text { Type of analysis, health care costs and non health care } \\
\text { costs [25]. }\end{array}$ & RQ4, RQ2 \\
$\begin{array}{c}\text { Legal, ethics } \\
\text { and moral } \\
\text { regulations }\end{array}$ & $\begin{array}{l}\text { Liability, privacy invasion, non-verbal language, non } \\
\text { appropriate contact, informed consent, computer fraud, } \\
\text { cyber security, potential torts, }\end{array}$ & RQ3, RQ4 \\
\hline
\end{tabular}

Table 3: Data extraction table (Cont.). 


\begin{tabular}{|c|c|c|c|}
\hline Category & Sub-category & Attribute & $\begin{array}{l}\text { Related } \\
\text { questions }\end{array}$ \\
\hline \multirow[t]{3}{*}{ Structure } & $\begin{array}{l}\text { Training of } \\
\text { medical } \\
\text { personnel }\end{array}$ & Manuals, books, on line or in situ courses, simulators & RQ4, RQ1 \\
\hline & $\begin{array}{l}\text { Health care } \\
\text { databases }\end{array}$ & Type of databases, type of information stored & $\begin{array}{l}\text { RQ1, } \\
\text { RQ2, } \\
\text { RQ3, RQ4 }\end{array}$ \\
\hline & $\begin{array}{l}\text { Communication } \\
\text { infrastructure }\end{array}$ & $\begin{array}{l}\text { Type of technology, network connections, speed of } \\
\text { transmission }\end{array}$ & \\
\hline \multirow[t]{4}{*}{ Process } & $\begin{array}{l}\text { Robotic } \\
\text { interaction }\end{array}$ & $\begin{array}{l}\text { Type of interactions with the patient, with the } \\
\text { environment, and feedback to the operator }\end{array}$ & RQ4 \\
\hline & $\begin{array}{l}\text { Medical } \\
\text { attention }\end{array}$ & $\begin{array}{l}\text { Type of health condition of the patient, type of medical } \\
\text { attention to the patient }\end{array}$ & RQ2 \\
\hline & Robot usability & $\begin{array}{l}\text { Cognitive load, learning curve in both operator and } \\
\text { interactants, error identification, recovery and prevention } \\
\text { capabilities }\end{array}$ & RQ1, RQ2 \\
\hline & $\begin{array}{l}\text { Access to } \\
\text { health care } \\
\text { databases }\end{array}$ & Type of retrieved data, display options & $\begin{array}{l}\text { RQ1, } \\
\text { RQ2, } \\
\text { RQ3, RQ4 }\end{array}$ \\
\hline
\end{tabular}

Table 3: Data extraction table (Cont.).

\begin{tabular}{|llll|}
\hline Category & Sub-category & Attribute & $\begin{array}{l}\text { Related } \\
\text { questions }\end{array}$ \\
\hline Outcomes & $\begin{array}{l}\text { Perception and } \\
\text { acceptance }\end{array}$ & $\begin{array}{l}\text { User satisfaction and technology acceptance from } \\
\text { physicians, patients, health workers }\end{array}$ & RQ2, RQ4 \\
$\begin{array}{l}\text { Healthcare } \\
\text { effects }\end{array}$ & $\begin{array}{l}\text { Patient mortality, overall health status of the patient } \\
\text { during the usage of the robot }\end{array}$ & $\begin{array}{l}\text { RQ1, RQ2, } \\
\text { RQ4 }\end{array}$ \\
\hline $\begin{array}{l}\text { Robot usage } \\
\text { time }\end{array}$ & & RQ2, RQ4 \\
\hline
\end{tabular}

\subsection{Collating, summarizing and reporting the results}

We propose both a basic quantitative analysis and a thematic synthesis [26] to summarize and report our findings. Quantitative analysis will be descriptive statistics representing data such as the studies found by year, country distribution, number of studies in which each attribute is considered, types of study design, satisfaction and acceptance of the stakeholders, medical conditions treated, patient mortality, and average robot usage. Table 4 is an example of a matrix that describes the number of research papers that study each attribute. This table will be useful to spot those robots features affecting one or more of the ICU related Donabedian categories. 
Thematic synthesis will be performed in 3 steps: 1) coding the text of the findings of each study, 2) organizing codes into a tree structure composed of descriptive themes and, at the same time, by establishing conceptual relationships (or translations) between studies; finally, 3) generating analytic themes that allow to transcend the synthesis of the original findings into new interpretations or concepts. This latter step will be carried out through periodical discussions to iteratively refine the analytic themes that cover and explain the descriptive themes. To do so we will use EPPI-Reviewer software [27]. Three of the authors will perform steps 1 to 3 . The rest of the team will track the progress and help to resolve any controversy whenever necessary. We propose thematic synthesis because it is an adequate approach to arise to new hypotheses [28], one of our most fundamental goals.

Table 4: Example of a summary table. 


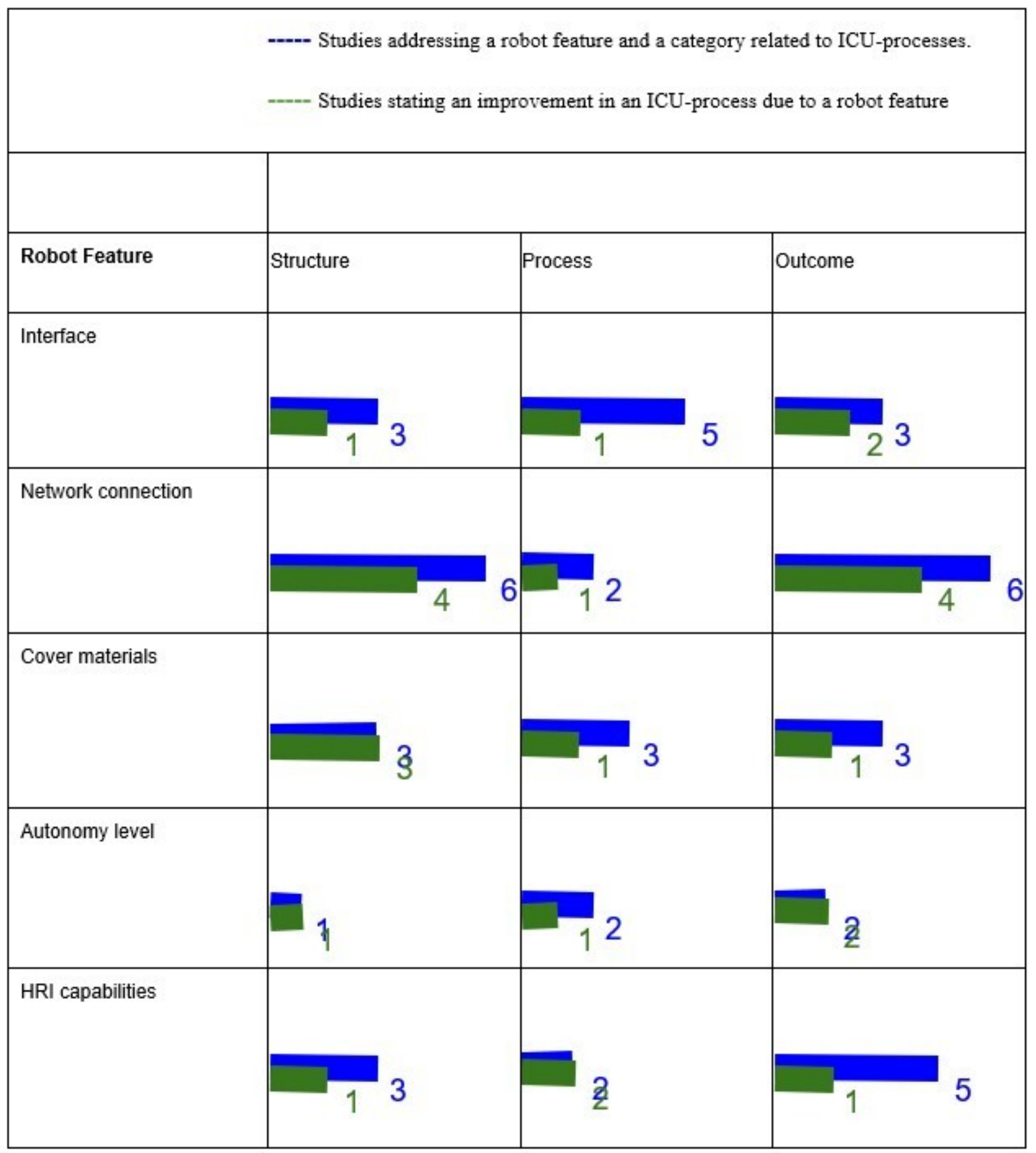

\subsection{Consultation with stakeholders}

During the entire process we are going to work closely with a group of two health specialists and one decision maker that is also a health professional, all of them experienced on either telepresence robots or robotics systems in medicine. We will keep them informed about our progress in order to receive continuous feedback.

\section{Discussion}


In our best knowledge, this will be the first scoping review devoted to identifying features of medical telepresence robotic systems that impact health care in ICUs. We will not evaluate the quality of the papers included as it is not strictly required in a scoping review. We propose to disseminate our work at international, national, and regional levels. Our results will be submitted to an international peer-reviewed journal and international conferences. At a national level, we will send our study to science news portals of our country of origin. Additionally, we will present this work in national discussion forums and scientific networks. At a regional level, we will organize at least one regional press conference and radio program, and include this study into the promotional activities to seek prospective students.

\section{Declarations}

\section{Contributors}

$\mathrm{HA}, \mathrm{SH}, \mathrm{HV}, \mathrm{GV}$ and MN conceived the study, contributed to conceptualize research objectives, questions and research designs, wrote parts of the document in accordance to their personal area of expertise, and provided critical revisions of the manuscript.

\section{Disclaimer}

The views expressed are those of the authors and do not necessarily represent the position of Universidad Politécnica de Victoria, Universidad de Xalapa, Universidad Popular Autónoma del Estado de Puebla, Universidad Nacional Autonoma de Mexico or Universidad Autonoma del Estado de Mexico.

\section{Consent for publication}

All authors agree to submit and publish the paper to BMC Systematic Reviews.

\section{Competing interests}

None declared.

\section{Ethics approval and consent to participate}

Not required.

\section{Funding}

None declared.

\section{Availability of data and materials}

This document is a protocol for a scoping review and no additional data is available yet. We would be very happy to share our document and reference databases upon completion of our work.

\section{Acknowledgements}


None declared.

\section{References}

1. Ono SK, Andraus W, Terrabuio DRB, et al. Technological Innovation in Outpatient Assistance for Chronic Liver Disease and Liver Transplant Patients During the Coronavirus Disease Outbreak: A Method to Minimize Transmission. Clinics 2020;75. doi:10.6061/clinics/2020/e1946

2. Costarides V, Guilcher T, Rebiaï M, et al. The ENDORSE concept, an integrated and mobile robotic solution, targeted at Medical Diagnostic support. 2019. https://hal.archives-ouvertes.fr/hal02161099/

3. Tsui KM, Yanco HA. Design Challenges and Guidelines for Social Interaction Using Mobile Telepresence Robots. Reviews of Human Factors and Ergonomics 2013;9:227-301.

4. Beer JM, Fisk AD, Rogers WA. Toward a Framework for Levels of Robot Autonomy in Human-Robot Interaction. Journal of Human-Robot Interaction. 2014;3:74. doi:10.5898/jhri.3.2.beer

5. van Kemenade M, Konijn EA, Hoorn J. Robots Humanize Care - Moral Concerns Versus Witnessed Benefits for the Elderly. In: Proceedings of the International Conference on Health Informatics. SCITEPRESS - Science and and Technology Publications 2015. 648-53.

6. Yang G-Z, Cambias J, Cleary K, et al. Medical robotics-Regulatory, ethical, and legal considerations for increasing levels of autonomy. Sci Robot 2017;2. doi:10.1126/scirobotics.aam8638

7. Vallès-Peris N, Domènech M. Roboticists' Imaginaries of Robots for Care: The Radical Imaginary as a Tool for an Ethical Discussion. Eng Stud 2020;:1-20.

8. Lee H, Kim J, Kim S, et al. Investigating the Need for Point-of-Care Robots to Support Teleconsultation. Telemed J E Health 2019;25:1165-73.

9. Lociciro A, Guillon A, Bodet-Contentin L. A telepresence robot in the room of a COVID-19 patient can provide virtual family presence. Can J Anaesth Published Online First: 8 June 2021. doi:10.1007/s12630-021-02039-6

10. Arksey H, O'Malley L. Scoping studies: towards a methodological framework. Int J Soc Res Methodol 2005;8:19-32.

11. Levac D, Colquhoun H, O'Brien KK. Scoping studies: advancing the methodology. Implement Sci 2010;5:69.

12. Peters MDJ, Godfrey $\mathrm{CM}$, Khalil $\mathrm{H}$, et al. Guidance for conducting systematic scoping reviews. Int J Evid Based Healthc 2015;13:141-6.

13. Peters MDJ, Godfrey C, Mclnerney P, et al. Chapter 11: scoping reviews. Joanna Briggs Institute Reviewer's Manual The Joanna Briggs Institute Published Online First: 2017. https:// wiki.jbi.global/display/MANUAL/Chapter+11\%3A+Scoping+reviews

14. Tricco AC, Lillie E, Zarin W, et al. PRISMA Extension for Scoping Reviews (PRISMA-ScR): Checklist and Explanation. Ann Intern Med 2018;169:467-73. 
15. Aromataris E, Riitano D. Constructing a search strategy and searching for evidence. Am J Nurs 2014;114:49-56.

16. Chambers. Chambers Crossword Dictionary. Hodder \& Stoughton 2012.

17. Chambers. The Chambers Thesaurus. Chambers 2012.

18. Real Academia Española. Diccionario de la lengua Española. Vigesimotercera edición. Versión normal. Grupo Planeta Spain 2016.

19. Röhrig B, du Prel J-B, Wachtlin D, et al. Types of Study in Medical Research. Deutsches Aerzteblatt Online. 2009. doi:10.3238/arztebl.2009.0262

20. Süt N. Study designs in medicine. Balkan Med J 2014;31:273-7.

21. Ht H, Harish HT, Librarian \& Head, et al. Zotero: Bibliographic Reference Management Software. Journal of Advanced Research in Library and Information Science. 2018;05:42-9. doi:10.24321/2395.2288.201807

22. Donabedian A. Evaluating the quality of medical care. 1966. Milbank Q 2005;83. doi:10.1111/j.14680009.2005.00397.x

23. Curry A, Flett P, Hollingsworth I. Managing Information and Systems: The Business Perspective. Taylor \& Francis 2006.

24. Liberati A, Altman DG, Tetzlaff J, et al. The PRISMA statement for reporting systematic reviews and meta-analyses of studies that evaluate healthcare interventions: explanation and elaboration. BMJ. 2009;339:b2700-b2700. doi:10.1136/bmj.b2700

25. Bergmo TS. How to Measure Costs and Benefits of eHealth Interventions: An Overview of Methods and Frameworks. J Med Internet Res 2015;17. doi:10.2196/jmir.4521

26. Thomas J, Harden A. Methods for the thematic synthesis of qualitative research in systematic reviews. BMC Medical Research Methodology. 2008;8. doi:10.1186/1471-2288-8-45

27. Thomas J, Brunton J, Graziosi S. EPPI-Reviewer 4.0: software for research synthesis. 2010.

28. Lucas PJ, Baird J, Arai L, et al. Worked examples of alternative methods for the synthesis of qualitative and quantitative research in systematic reviews. BMC Med Res Methodo/ 2007;7:1-7.

\section{Figures}

\section{Image not available with this version}

Figure 1 
Caption not included with this version.

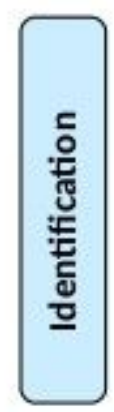

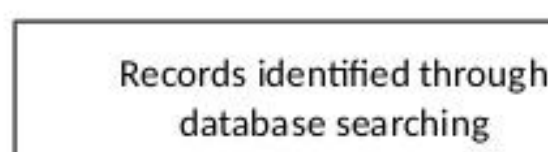

$$
(n=)
$$
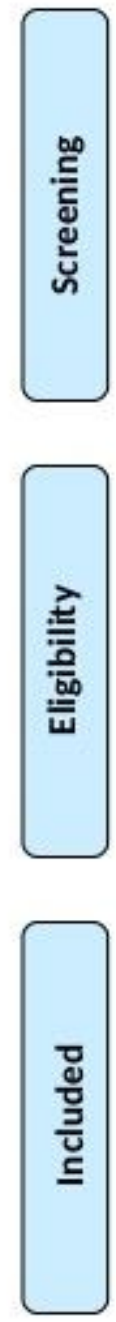

Additional records identified through other sources

$$
(n=)
$$

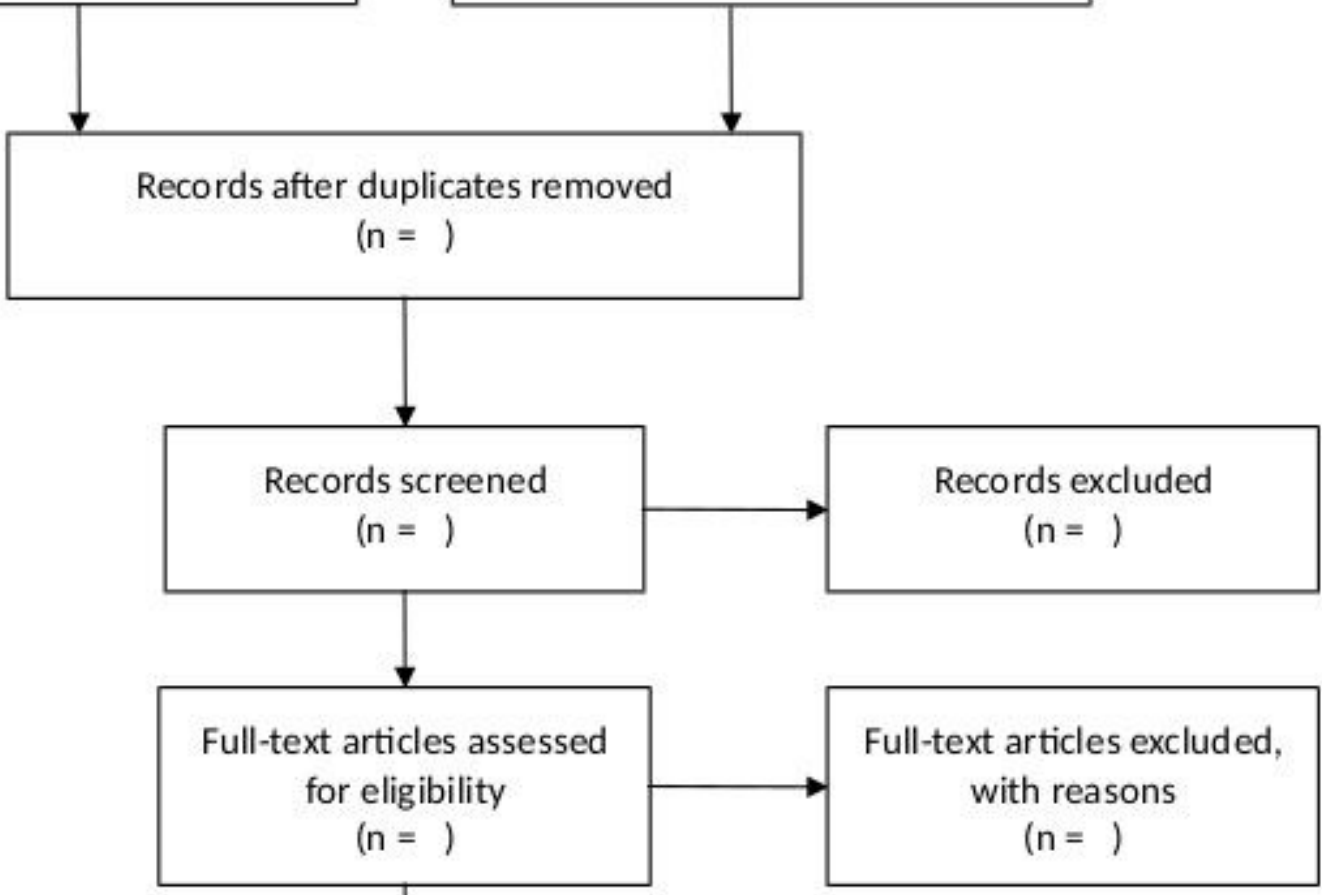

\section{Figure 2}

PRISMA flow diagram [24] that describes the paper selection process adapted for scoping reviews [13]. 